one on each temple. Two morning applications gave her relief for the day, but the pain came on again at night for three days she was treated twice a day, for nine days once a day, and for a few days longer on alternate days. Except for a few short attacks soon after treatment commenced she had no further pain.

In cases of bladder trouble it has not proved so successful in our hands as is reported from other sources, but one case is worthy of note.

CASE 5.-J. K., a hard-working, sensible girl, had been troubled all her life with frequent micturition, having during cold and damp weather to micturate every ten minutes. For some years past she had to stop from work during winter months. The whole trouble was to stop from work during winter months. The whole trouble was purely norvous. She had had various medical treatments and had been in nursing homes, receiving little or no benete. Wo applied one pad over the lumbar region and the other two well down over the pubes, taking care that they did not touch each other and (as in all cases where it is suspected that the nerves are at fault) the current was used as rapid as possible. This patient improved at once and was able to keep to her work all the winter, but if the treatment stopped for a fortnight she began to relapse, which resulted in her coming for treatment two or three times a week during the cold months.

This form of electrical treatment gives relief in pains of rheumatoid arthribis but we have not been able to give it a fair trial in this class of disease. We ought to mention some difficulties that may arise in treatment. If there is the least break in the cuticle, as a scratch or pimple, the current is painful at this point; such places are best protected with rubber strapping. Laparotomy scars also often give confiderable pain during treatment.

The following is a tabulated list of the cases which have been treated with this combination wave-current :-

\begin{tabular}{|c|c|}
\hline Condition. & Result. \\
\hline Constipation with atony of colon. & Recovery 88 per cent. \\
\hline $\begin{array}{c}\text { Alternating constipation and } \\
\text { diarrhoea. }\end{array}$ & Unsatisfactory. \\
\hline Nervous debility. & Recovery 70 per cent. \\
\hline $\begin{array}{c}\text { Alcoholic neuroses and general } \\
\text { paralysis of the insane. }\end{array}$ & Nil. \\
\hline Rheumatoid arthritis. & Appears to be beneficial. \\
\hline Dyspepsia. & ,,$\quad$, \\
\hline Enuresis. & $\left\{\begin{array}{c}\text { Improvement while under treats } \\
\text { ment } 80 \text { per cent. }\end{array}\right.$ \\
\hline
\end{tabular}

Liseard.

\section{NOTES ON A CASE OF ACCIDENTAL POISONING BY CHLORIDE OF ANTIMONY.}

By J. MID DLET ON, M.D. EDIN.

ON account of the clinical features presented, not less than the comparative rarity of accidental poisoning by the salts of antimony, it appears desirable to place on record the following case which recently came under observation.

About 4 P.M., during the temporary absence of the mother in an adjoining part of the house, a male child, aged 16 months-the child is said to have walked since he was nine months old-crawled from his cradle placed on the floor, crossed the apartment, and mounting on a chair managed to reach the top of a dresser standing fully four feet high, near the centre of which stood a firmlycorked bottle containing a preparation which the father, a shepherd, was in the habit of using as a dressing for the feet of sheep affected with foot-rot. Withdrawing the cork, the child put the bottle into his mouth and swallowed a portion of its contents, whereupon the mother was attracted by his screams. It is, of course, very difficult, if not absolately impossible, to estimate with any measure of accuracy the actual amount of the poison swallowed, but making full allowance for what was spilt on the child's clothes and about him, and having regard to the father's estimate of the quantity contained in the bottle, which had been reduced by fully three tablespoonfuls, it appears probable that the child must have swallowed at least two teaspoonfuls of the liquid. About half an hour before taking the poison the child had a small quantity of milk and a little bread and butter.

Immediately upon discovering what had happened the friends administered hot salt and water and continued to do so at short intervals till my arrival. I then learned that the child had vomited pretty frequently and that the vomit which at first appeared to contain little else than partidles of bread and curdled milk, gradually changed to a dark coffeeground appearance, and this statement I was able to confirm by an examination of the earlier and later vomits, all of which had been retained for inspection. The bottle from which the child had drunk was found to be correctly and carefully labelled " butter of antimony," and still contained about three ounces of a dark orange-coloured fluid, a few drops of which when added to water yielded a whitishyellow precipitate. When seen about an hour after the poison had been taken the child presented the following symptoms. He lay in a heavy, drowsy state extended on the knees of a neighbour, his head being thrown forcibly back, from time to time exhibiting a struggling and choking sensation, clutching at and complaining of pain in his throat. The lower limbs were alternately forcibly extended or drawn upwards and flexed over the abdomen. Both upper and lower extremities were markedly and persistently cold. The pulse was barely perceptible; the pupils were widely dilated and inactive and there were frequent muscular twitchings. The general condition, indeed, was one of pronounced collapse. The chin, lips, tongue, the whole interior of the mouth, and the fauces were whitened in the same manner as by the action of strong carbolic acid and there was some difficulty in swallowing, accompanied by considerable regurgitation from the nares. There was a very marked tendency to doze but the child could be readily roused to take fluids, his thirst being intense. The vomiting of dark coffeeground matter continued, though at lengthening intervals, during the greater part of the following day and diarrhoa presenting similar characteristics set in about 16 hours after the poison had been taken and persisted for fully 48 hours. Even after the diarrhœea was checked the fæces continued for some days to present a preternaturally dark colour. When the vomited matter was submitted to Reinsch's process abundant evidence was afforded of the presence of antimony, and the urine when similarly treated pielded traces of the metal during the two following days The child was fed with milk and white of egg for the first 24 hours, after which barley water or rice water was added. A mixture containing equal parts of compound tincture of cinchona and tincture of calumba was given first at short and later at gradually lengthening intervals, and in about a week from the taking of the poison the child was apparently in his normal health and taking his customary food.

Manorhead, Stow.

\section{A CASE OF RHEUMATIC HYPERPYREXIA.}

By Thos. E. B. Meyler, L.R.C.P. \& S. IREL.

THE rarity of hyperpyrexia during the course of acute rheumatism in children makes any example worth recording.

The patient, a boy aged nine years, was seen by me for the first time on August 30th, 1908. For the past seven weeks he had complained of a stiff neck, which was painful on movement, and of slight pain in the legs, but he was able to attend school. I was called in because when he awoke in the morning he could not move the left arm. I found him in bed, free from pain except in the neck which was not swollen or tender. The pulse-rate was 136 and the temperature was $99 \cdot 6^{\circ} \mathrm{F}$. The tongue was clean and the patient was perspiring. The apex beat was in the left nipple line, about one inch lower than the normal. Impulse was forcible but there was no thrill. The aortic second sound was clear. There was a loud mitral pre-systolic murmur and a systolic murmur was well heard at the left scapular angle. The lungs were healthy. The left upper extremity was completely paralysed and flaccid. The other limbs were not affected. The urine was high-coloured and was free from albumin. There was no change in the condition of the patient until Sept. 3rd, when I was hastily called to him at 6 A.M. I found him deeply comatose and breathing stertorously. The pupils were contracted, the face was cyanosed, and the skin was hot and very dry. The temperature was $109 \cdot 2^{\circ}$ and the pulse was uncountable. Violent purging took place. Ice not being available cold sponging was used, but the patient died in an hour, the temperature rising to $110^{\circ}$ just before death.

Experience has shown that hyperpyrexia is most frequent in first attacks of rheumatism, also in cases which run a mild course. Both these points are illustrated by this case. Chevening+road, w 